\title{
TEOR TOTAL E CAPACIDADE MÁXIMA DE ADSORÇÃO DE CHUMBO EM LATOSSOLOS BRASILEIROS ${ }^{(1)}$
}

\author{
M. A. P. PIERANGE LI (2), L. R. G. GUILHERME (3), \\ N. CURI (3), M. L. N.SILVA(3), L. R. OLIVEIRA ${ }^{(4)}$ \& J . M. LIMA ${ }^{(3)}$
}

\begin{abstract}
RESUMO
O teor total e a capacidade máxima de adsorção de chumbo $(\mathrm{Pb})$ dos solos são influenciados pelos seus atributos físicos, químicos e mineralógicos e o seu conhecimento é de fundamental importância para estudos da dinâmica do $\mathbf{P b}$ no meio ambiente. Neste estudo, determinaram-se o teor total e a capacidade máxima de adsorção de $\mathrm{Pb}$ (CMAPb) de Latossolos de várias regiões geográficas do Brasil e correlacionaram-se os valores de CMAP b com os seus atributos físicos, químicos e mineralógicos. O teor total variou de 6,14 a $30,55 \mathrm{mg} \mathrm{kg}^{-1}$, com média de $18,00 \mathrm{mg} \mathrm{kg}^{-1}$, verificando-se os maiores teores em solos das regiões sul e sudeste. A CMAPb variou de 2.115 a $19.465 \mathrm{mg} \mathrm{kg}^{-1}$, com média de $11.296 \mathrm{mg} \mathrm{kg}^{-1}$, apresentando correlação negativa com as relações $\mathrm{Al}_{2} \mathrm{O}_{3} / \mathrm{Fe}_{2} \mathrm{O}_{3}$ e Gt/(Gt $\left.+\mathrm{Hm}\right)$ e correlação positiva com Si e Fe, extraídos por ataque sulfúrico, $\mathrm{Fe}$, extraído pelo oxalato ácido de amônio e ditionito-citrato-bicarbonato de sódio, caulinita e hematita, bem como com os valores de CTC e superfície específica. Os solos estudados apresentaram grande capacidade de retenção de $\mathbf{P b}$, tendo os Latossolos Roxos e Latossolos Vermelho-E scuros apresentado maiores CMAPb que os Latossolos Vermelho-Amarelos e Latossolo Amarelo. Adicionalmente, a maioria dos solos apresentou CMAPb maior que a CTC a pH 7,0, o que pode ser um indicativo de que parte do $\mathrm{Pb}$ é adsorvido como complexo de esfera interna.
\end{abstract}

Termos de indexação: metal pesado, solos tropicais, mineralogia do solo.

(1) Extraído da Tese de Mestrado apresentada pelo primeiro autor à Universidade Federal de Lavras - UFLA. Financiado por FAPEMIG e CNPq. Recebido para publicação em março de 2000 e aprovado em dezembro de 2000.

(2) Doutoranda em Solos e Nutrição de Plantas, Universidade Federal de Lavras - UFLA. Caixa Postal 37, CEP 37200-000 Lavras (MG). Bolsista da FAPEMIG. E-mail: mapp@ufla.br

(3) Professor do Departamento deCiência doSolo, UFLA. Bolsista doCNPq. E-mails: guilherm@ufla.br; niltcuri@ufla.br; marx@ufla.br; imlima@ufla.br

(4) Estudante de Engenharia Agrícola da UFLA - Bolsista de Iniciação Científica do CNPq. E-mail: leyser@ufla.br 


\title{
SUMMARY: TOTAL LEAD CONTENT AND MAXIMUM ADSORPTION CAPACITY IN BRAZILIAN OXISOLS
}

\begin{abstract}
Total soil lead $(\mathrm{Pb})$ content al ong with thesorption capacity of $\mathrm{Pb}$ in soils areimportant parameters for risk assessment studies of $\mathrm{Pb}$ in the environment. This experiment used $\mathrm{A}$ horizon samples of 17 Oxisol s from all Brazilian regi ons to eval uate their total $\mathrm{Pb}$ content as well as their $\mathrm{Pb}$ maximum adsorption capacities (PbMAC). The total soil Pb content varied from 6.14 to $30.55 \mathrm{mg} \mathrm{kg}^{-1}$, averaging $18.00 \mathrm{mg} \mathrm{kg}^{-1}$. Thehighest total soil Pb contents werefound for soils of thesouthern and southeastern regi ons, fol lowed by thesoils from the western Central and northern/ Northeast regions. Values of the PbMAC varied from 2,215 to $19,465 \mathrm{mg} \mathrm{kg}^{-1}$, averaging $11,296 \mathrm{mg} \mathrm{kg}^{-1}$. Lead maximum adsorption capacity was positive y corre ated with sulfuric acid digesti on-Si and -Fe, oxalate and DCB-Fe, hematite, kaol initeand clay contents, CEC and specific surface area val ues and negati vely correlated with $\mathrm{Al}_{2} \mathrm{O}_{3} / \mathrm{Fe}_{2} \mathrm{O}_{3}$ and $\mathrm{Gt} /(\mathrm{Gt}+\mathrm{Hm}$ ). Theresults indicated that Oxisols can adsorb a great amount of $\mathrm{Pb}$. In addition, it was observed that most Oxisols adsorbed more $\mathrm{Pb}$ than the amount expected from CEC values, which indicates the occurrence of inner-sphere complexation.
\end{abstract}

Index terms: heavy metal, tropical soils, soil mineral ogy.

\section{INTRODUÇÃO}

O chumbo é um metal pesado potencialmente tóxico para homens e animais. Por isso, o seu uso tende a ser restringido como forma de minimizar os riscos decorrentes do seu acúmulo em solos, água e ar. Algumas fontes esuas respectivas concentrações (base seca) de chumbo são: inseticidas $\left(\mathrm{PbHAsO}_{4}\right)=$ $600.000 \mathrm{mg} \mathrm{kg}^{-1}$; biossólidos = 29 a $3.600 \mathrm{mg} \mathrm{kg}^{-1}$; cal cários =20 a $2.827 \mathrm{mg} \mathrm{kg}^{-1}$; compostos orgânicos $=1,3$ a $2.240 \mathrm{mg} \mathrm{kg}^{-1}$; fertilizantes =2 a $275 \mathrm{mg} \mathrm{kg}^{-1}$ (Alloway, 1990; Amaral Sobrinhoet al ., 1992; KabataPendias \& Pendias, 1992).

No Brasil, teores de chumbo superiores aos reportados na literatura mundial têm sido observados em alguns fertilizantes e calcários (Amaral Sobrinho et al., 1992), biossólidos (Langenbach et al., 1994) e compostos delixo urbano (Cravo et al., 1998). E mbora existam normas regulamentares relativas à concentração máxima permitida de $\mathrm{Pb}$ para que um resíduo ou corretivo possa ser adicionado aos solos, elas são muito genéricas, uma vez que não levam em conta os atributos dos solos.

Horizontes superficiais dos solos têm grande afinidade para acumular $\mathrm{Pb}$ proveniente de deposições atmosféricas ou de fontes industriais e agrícolas (Kabata-Pendias \& Pendias, 1992; Abreu et al., 1998), graças, principalmente, à baixa solubilidade do el emento e à forte adsorção ao solo (Chaney, 1991). Como conseqüência, teores tão altos quanto $3.916 \mathrm{mg} \mathrm{kg}^{-1}$ de $\mathrm{Pb}$, em regiões agrícolas, ou $135.000 \mathrm{mg} \mathrm{kg}^{-1}$ de $\mathrm{Pb}$, em regiões industriais, têm sido reportados (Kabata-Pendias \& Pendias, 1992).

O entendimento dos processos de adsorção e dessorção de metais é fundamental na remediação de áreas contaminadas, bem como na prevenção de futuras contaminações. Metais pesados presentes em baixas concentrações tendem a ser retidos no solo via adsorção, principal menten na forma não-trocável (McBride, 1989). As reações de adsorção entre íons metálicos e superfícies envolvem tanto a formação de complexos de esfera externa, através de troca de cátions, cujas ligações são relativamente fracas, quanto a formação de complexos de esfera interna, através de troca de ligantes ou ligações covalentes, com ligações extremamente fortes (McBride, 1994).

O chumbo, como outros elementos catiônicos, é retido primeiramente nas cargas negativas das superfícies dos colóides do solo, formando, posteriormente, ligações mais estáveis. Nesteúltimo caso, ele passa a fazer parte da superfície dos colóides e torna-se pouco disponível para as plantas. Sua liberação para a solução do solo é governada por princípios de produtos desolubilidade, sendo afetada por mudanças nas condições do meio, tais como: pH, propriedades de superfície dos constituintes do solo e força iônica da solução.

Estudos realizados com materiais puros têm mostrado que o chumbo é o metal pesado mais fortemente adsorvido pela hematita (McKenzie, 1980). Já pela goethita (McKenzie, 1980) e ácidos húmicos (Stevenson, 1976), somente o cobre é mais fortemente retido que o chumbo. Zimdahl \& Skogerboe (1977), investigando a capacidade máxima de adsorção de $\mathrm{Pb}$ por 17 solos minerais e um solo orgânico de região de clima temperado, encontraram que esta poderia ser predita pela CTC e pH.

A importância dos óxidos de ferro na adsorção de metais tem sido relatada em literatura ( enne, 1998; Axe \& Anderson, 1998). Guy \& Chakrabarti (1976), 
citados por Axe \& Anderson (1998), indicam a seguinteordem de capacidadeadsortiva para metais: óxidos/hidróxidos > substâncias húmicas > argilas silicatadas.

A grande capacidade dos solos em adsorver $\mathrm{Pb}$, avaliada por meio de isotermas de Langmuir, tem sido bem documentada em sol os de clima temperado. Basta \& Tabatabai (1992) encontraram valores de CMAPb de até $20.720 \mathrm{mg} \mathrm{kg}^{-1} \mathrm{em}$ sol os localizados em I owa (EUA). Harter (1979), estudando a capacidade de adsorção de $\mathrm{Pb}$ de vários solos dos EUA, encontrou valores variando de 1.450 a $52.629 \mathrm{mg} \mathrm{kg}^{-1}$. Zimdahl \& Skogerboe (1977), trabal hando com 18 sol os de várias regiões dos EUA, verificaram que a CMAPb variou de 3.108 a $29.008 \mathrm{mg} \mathrm{kg}^{-1}$.

Em sol os tropicais, mais intemperizados, maior ênfase sempre foi dada para a capacidade máxima de adsorção de ânions, como o fosfato (Souza et al., 1991). Matos (1995), medindo a adsorção de vários metais pesados em três sol os com Bt eL atossol os da região de Viçosa (MG), verificou uma grande capacidade adsortiva destes solos para $\mathrm{Pb}$ e Zn.

O objetivo deste trabalho foi determinar o teor total e a capacidade máxima de adsorção de $\mathrm{Pb}$ (CMAPb) de Latossol os brasileiros, considerando um mesmo valor de $\mathrm{pH}$ e força iônica da solução de equilíbrio, bem como correlacionar os valores de CMAPb com os seus atributos.

\section{MATERIAL E MÉTODOS}

Foram utilizadas amostras da camada superficial (0-0,20 m) de 17 Latossolos localizados em áreas experimentais de várias regiões geográficas do Brasil. A classificação dos solos, sua localização e respectivos materiais de origem encontram-se no quadro 1.

\section{Quadro 1. Classificação e localização dos solos estudados}

\begin{tabular}{|c|c|c|c|}
\hline Solo & Classificação & Localização & Material de origem \\
\hline 1 & $\begin{array}{l}\text { Latossolo Roxo distrófico textura argilosa fase floresta } \\
\text { subtropical }\end{array}$ & Ijuí-RS & Basalto \\
\hline 2 & $\begin{array}{l}\text { Latossolo Vermel ho-E scuro distrófico textura argilosa fase } \\
\text { floresta subtropical }\end{array}$ & Passo Fundo-RS & Basalto e arenito (mistura) \\
\hline 3 & $\begin{array}{l}\text { Latossolo Roxo distrófico textura argi losa fase floresta } \\
\text { subtropical alta mista com araucária }\end{array}$ & Chapecó-SC & Basalto \\
\hline 4 & $\begin{array}{l}\text { Latossolo Vermelho-Escuro distrófico textura argilosa fase } \\
\text { floresta tropical perenifólia }\end{array}$ & Ponta Grossa-PR & Rochas diversas do Pré-cambriano \\
\hline 5 & $\begin{array}{l}\text { Latossolo Roxo eutrófico textura argilosa fase floresta } \\
\text { tropical subperenifólia }\end{array}$ & Londrina-PR & Basalto, meláfiro e diabásio \\
\hline 6 & $\begin{array}{l}\text { Latossolo Vermel ho-Escuro álico textura média fase } \\
\text { floresta tropical subperenifólia }\end{array}$ & Paranavaí-PR & Arenito Caiuá \\
\hline 7 & $\begin{array}{l}\text { Latossolo Roxo eutrófico textura muito argilosa fase } \\
\text { floresta subperenifólia }\end{array}$ & Dourados-MS & Rochas eruptivas básicas \\
\hline 8 & $\begin{array}{l}\text { Latossolo Roxo eutrófico textura muito argilosa fase } \\
\text { floresta tropical subcaducifólia }\end{array}$ & Campinas-SP & Diabásio \\
\hline 9 & $\begin{array}{l}\text { Latossolo Vermel ho-E scuro distrófico textura argilosa fase } \\
\text { floresta latifoliada tropical }\end{array}$ & J aboticabal-SP & Basalto, com influência de arenito \\
\hline 10 & $\begin{array}{l}\text { Latossolo Vermelho-E scuro distrófico textura muito } \\
\text { argilosa fase cerrado }\end{array}$ & Lavras-MG & Gnaisse granítico mesocrático \\
\hline 11 & $\begin{array}{l}\text { Latossolo Vermelho-Amarelo distrófico textura muito } \\
\text { argilosa fase cerrado }\end{array}$ & Lavras-MG & Gnaisse granítico leucocrático \\
\hline 12 & $\begin{array}{l}\text { Latossolo Vermelho-E scuro álico textura muito argilosa } \\
\text { fase cerrado tropical subcaducifól io }\end{array}$ & Sete Lagoas-MG & Rochas pelíticas do Grupo Bambuí \\
\hline 13 & $\begin{array}{l}\text { Latossolo Vermel ho-E scuro distrófico textura argilosa fase } \\
\text { cerrado tropical subcaducifólio }\end{array}$ & Goiânia-GO & $\begin{array}{l}\text { Sedimentos argilosos } \\
\text { retrabalhados }\end{array}$ \\
\hline 14 & $\begin{array}{l}\text { Latossolo Vermel ho-Escuro álico textura argilosa fase } \\
\text { cerradão subcaducifólio }\end{array}$ & Planaltina-DF & Sedimentos argilosos de cobertura \\
\hline 15 & $\begin{array}{l}\text { Latossolo Vermelho-Amarelo álico textura média fase } \\
\text { floresta subperenifólia }\end{array}$ & Areia-PB & Sedimentos areno-argilosos \\
\hline 16 & $\begin{array}{l}\text { Latossolo Vermel ho-Amarelo distrófico textura média fase } \\
\text { floresta subperenifólia }\end{array}$ & Ubajara-CE & Arenito \\
\hline 17 & $\begin{array}{l}\text { Latossolo Amarelo álico textura argilosa fase floresta } \\
\text { equatorial subperenifólia }\end{array}$ & Tomé Açu-PA & Sedimentos do Terciário \\
\hline
\end{tabular}


Na fraçãoterra fina seca ao ar, foram determinados óxidos de Si, Al e Fe extraídos pel o ataque sulfúrico (EMBRAPA, 1997).

$\mathrm{Na}$ fração argila, foi feita determinação de $\mathrm{Fe}$ extraído pelo ditionito-citrato-bicarbonato de sódio (Fe-DCB) (Mehra \& J ackson, 1960) e oxalato ácido de amônio (Fe-Ox) (Schwertmann, 1964), obtendose os teores de óxidos livres totais e de óxidos menos cristal inos, respectivamente. A determinação do Fe foi feita por espectrofotometria de absorção atômica.

Na fraçãoargila desferrificada, foramidentificadas caulinita (Ct), gi bbsita (Gb) e vermiculita com hidróxi entre-camadas $(\mathrm{Vm}-\mathrm{OH})$ por meio de difração de raios-X (algumas amostras são mostradas na Figura 1), sendo a Ct ea Gb semiquantificadas pela análise térmica diferencial e a $\mathrm{Vm}-\mathrm{OH}$ pela intensidade relativa de seus reflexos.

A identificação ea semiquantificação da hematita $(\mathrm{Hm})$, goethita (Gt) e maghemita ( $\mathrm{Mh}$ ) foram feitas por meio da difratrometria de raios-X (algumas amostras são mostradas na Figura 2), após concentração dos óxidos de ferro na fração argila, conforme Kämpf \& Schwertmann (1982). Todos os valores determinados na fração argila foram corrigidos para terra fina seca em estufa e todas as análises foram feitas com quatro repetições.

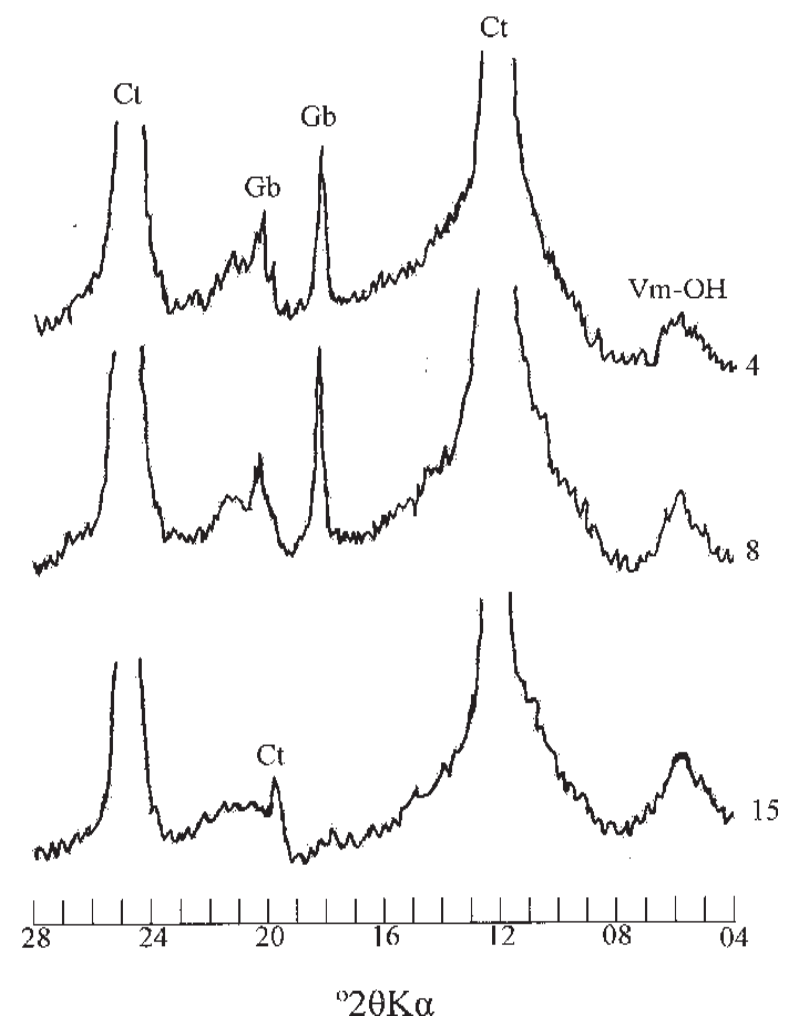

Figura 1. Difratogramas de raios-X de lâminas orientadas da fração argi la desferrificada dos solos 15, 8 e 4. Vm-OH =vermiculita com hidróxi entre-camadas; $\mathbf{C t}=$ caulinita; $\mathbf{G b}=$ gi bbsita.
A matéria orgânica e a CTC a pH 7,0 foram determina-das segundo Vettori (1969) eEMBRAPA (1997).

A análise granulométrica dos solos foi realizada pelo método da pi peta (Day, 1965), empregando-se $\mathrm{NaOH}$ 0,01 mol L-1 como dispersante e agitação (12.000 rpm) durante 10 min. A superfície específica foi determinada na terra fina seca ao ar, segundo o método proposto por Heilman et al. (1965), que utiliza o éter monoetílico do etileno glicol (EMEG), como fase adsortiva.

A caracterização química, física e mineralógica dos sol os é apresentada nos quadros 2 e 3.

A determinação do teor total de $\mathrm{Pb}$ nos solos foi realizada por espectrofotometria de absorção atômica, após extração com água régia (Ure, 1990), utilizando-se $3 \mathrm{~g}$ de terra fina seca ao ar, os quais foram colocados em erlenmeyer com capacidade de $100 \mathrm{~mL}$, adicionando-se $2 \mathrm{~mL}$ de água destilada e $28 \mathrm{~mL}$ de solução de água régia. A pós fervura branda por duas horas, o material contido no erlenmeyer foi filtrado, lavando-se o resíduo do frasco e do filtro com $15 \mathrm{~mL}$ de $\mathrm{HNO}_{3}$ 0,5 mol L-1 e água destilada até completar ovolume do filtrado para $100 \mathrm{~mL}$. Para minimizar a perda do material durante a fervura, os frascos foram tampados com funil.
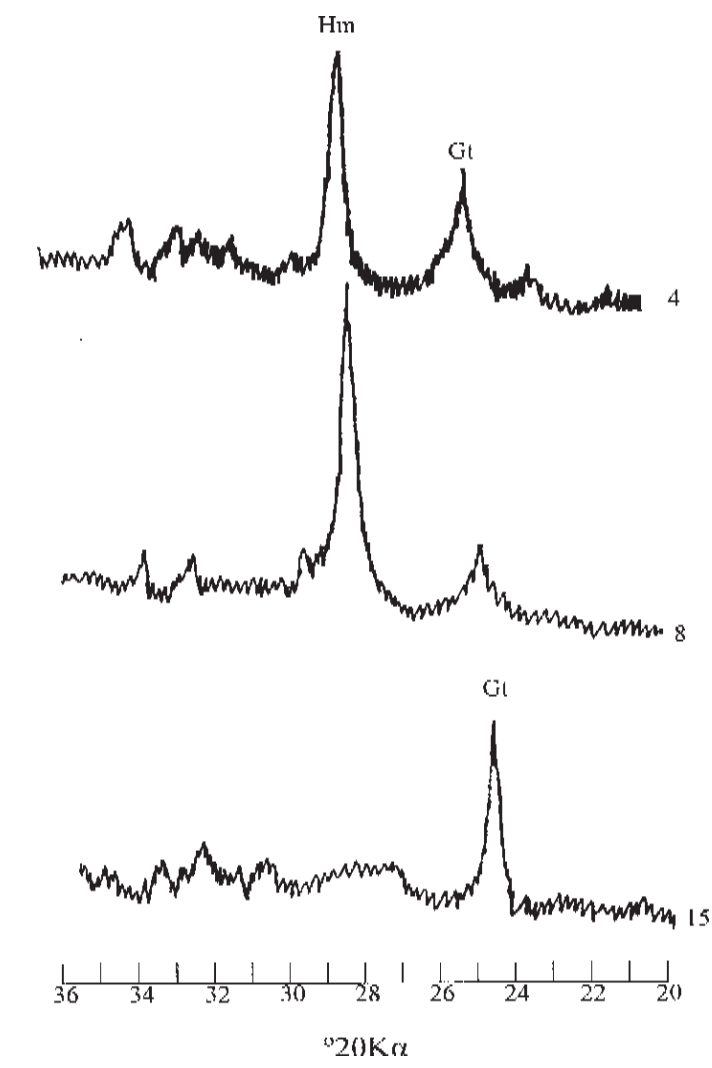

Figura 2. Difratogramas de raios-X, pelo método do pó, da fração argila ferro-concentrada dos solos 15, 8 e 4. Gt = goethita; Hm = hematita. 
Quadro 2. Atributos químicos, físicos e mineralógicos e relações destes para os Latossolos estudados ${ }^{(1)}$

\begin{tabular}{|c|c|c|c|c|c|c|c|c|c|c|c|c|c|c|c|c|c|c|}
\hline \multirow{2}{*}{ Solo } & \multicolumn{6}{|c|}{ Mineralogia } & \multicolumn{3}{|c|}{ Ataque sulfúrico } & \multicolumn{2}{|c|}{$\mathrm{Fe}_{2} \mathrm{O}_{3}$} & \multirow{2}{*}{$F e_{d} / F e_{s}$} & \multirow{2}{*}{$F e_{o} / F e_{d}$} & \multirow{2}{*}{$\mathbf{K i}$} & \multirow{2}{*}{$\mathbf{K r}$} & \multirow{2}{*}{$\mathbf{T}$} & \multirow{2}{*}{ SE } & \multirow{2}{*}{ MO } \\
\hline & Vm-OH & $\mathbf{C t}$ & Gb & Gt & $\mathrm{Hm}$ & Mh & $\mathrm{SiO}_{2}$ & $\mathrm{Al}_{2} \mathrm{O}_{3}$ & $\mathrm{Fe}_{2} \mathrm{O}_{3}$ & DCB & Ox & & & & & & & \\
\hline & & & & & & $\mathrm{kg}^{-1}$ & & & & & 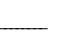 & & & & & $\mathrm{mmol}_{\mathrm{c}} \mathrm{kg}^{-1}$ & $\mathrm{~m}^{2} \mathrm{~g}^{-1}$ & $\mathrm{~g} \mathrm{~kg}^{-1}$ \\
\hline 1 & 66 & 421 & 58 & 10 & 107 & 8 & 199 & 182 & 210 & 80 & 3,7 & 0,38 & 0,05 & 1,9 & 0,9 & 148 & 187,6 & 26 \\
\hline 2 & 26 & 254 & 95 & 6 & 89 & 0 & 149 & 143 & 63 & 38 & 2,8 & 0,60 & 0,07 & 1,8 & 1,2 & 181 & 139,7 & 31 \\
\hline 3 & 121 & 526 & 61 & 4 & 71 & 7 & 246 & 217 & 139 & 62 & 2,7 & 0,44 & 0,08 & 1,9 & 1,2 & 158 & 196,6 & 45 \\
\hline 4 & 14 & 344 & 172 & 42 & 58 & 0 & 172 & 220 & 178 & 87 & 2,5 & 0,49 & 0,03 & 1,3 & 0,7 & 79 & 166,1 & 22 \\
\hline 5 & 75 & 420 & 225 & 11 & 122 & 8 & 253 & 270 & 268 & 119 & 6,0 & 0,44 & 0,05 & 1,6 & 0,8 & 104 & 182,3 & 14 \\
\hline 6 & 13 & 103 & 11 & 2 & 9 & 0 & 42 & 66 & 27 & 11 & 0,7 & 0,41 & 0,06 & 1,1 & 0,8 & 41 & 90,4 & 9 \\
\hline 7 & 36 & 402 & 112 & 11 & 79 & 10 & 203 & 213 & 301 & 76 & 3,2 & 0,25 & 0,04 & 1,6 & 0,7 & 117 & 169,9 & 13 \\
\hline 8 & 13 & 312 & 180 & 34 & 61 & 0 & 161 & 208 & 178 & 78 & 3,0 & 0,44 & 0,04 & 1,3 & 0,7 & 86 & 166,6 & 26 \\
\hline 9 & 9 & 171 & 141 & 3 & 15 & 0 & 114 & 192 & 100 & 51 & 2,1 & 0,51 & 0,04 & 1,0 & 0,7 & 66 & 147,0 & 29 \\
\hline 10 & 11 & 190 & 484 & 16 & 19 & 0 & 159 & 270 & 125 & 46 & 2,2 & 0,37 & 0,05 & 1,0 & 0,7 & 60 & 156,1 & 33 \\
\hline 11 & 19 & 305 & 374 & 22 & 0 & 0 & 141 & 330 & 110 & 60 & 0,3 & 0,54 & 0,05 & 0,7 & 0,5 & 64 & 182,6 & 48 \\
\hline 12 & 18 & 491 & 254 & 14 & 73 & 0 & 234 & 319 & 120 & 73 & 3,4 & 0,61 & 0,05 & 1,2 & 0,9 & 41 & 171,6 & 38 \\
\hline 13 & 2 & 19 & 448 & 26 & 45 & 0 & 95 & 241 & 108 & 59 & 2,2 & 0,55 & 0,04 & 0,7 & 0,5 & 74 & 145,3 & 30 \\
\hline 14 & 40 & 360 & 75 & 17 & 29 & 0 & 150 & 187 & 88 & 52 & 3,1 & 0,59 & 0,06 & 1,4 & 0,9 & 103 & 159,8 & 41 \\
\hline 15 & 17 & 420 & 0 & 3 & 0 & 0 & 135 & 149 & 39 & 15 & 1,8 & 0,38 & 0,12 & 1,5 & 1,2 & 110 & 162,9 & 43 \\
\hline 16 & 2 & 69 & 69 & 10 & 0 & 0 & 46 & 75 & 15 & 09 & 0,9 & 0,60 & 0,10 & 1,0 & 0,9 & 88 & 91,0 & 26 \\
\hline 17 & 27 & 327 & 0 & 6 & 0 & 0 & 124 & 135 & 33 & 10 & 0,7 & 0,30 & 0,07 & 1,6 & 1,2 & 88 & 103,1 & 16 \\
\hline
\end{tabular}

(1) $\mathrm{Vm}-\mathrm{OH}$ = vermiculita com hidróxi entre-camadas; $\mathrm{Ct}=$ caulinita; $\mathrm{Gb}=$ gibbsita; $\mathrm{Gt}=$ goethita; $\mathrm{Hm}=$ hematita; $\mathrm{Mh}=$ maghemita; $\mathrm{ki}=$ relação molecular $\mathrm{SiO}_{2} / \mathrm{Al}_{2} \mathrm{O}_{3} ; \mathrm{kr}=$ relação molecular $\mathrm{SiO}_{2} /\left(\mathrm{Al}_{2} \mathrm{O}_{3}+\mathrm{Fe}_{2} \mathrm{O}_{3}\right) ; \mathrm{Fe}_{\mathrm{d}}=\mathrm{Fe}_{2} \mathrm{O}_{3}$ extraído pelo ditionito citrato bicarbonato (DCB); $\mathrm{Fe}_{\mathrm{o}}=\mathrm{Fe}_{2} \mathrm{O}_{3}$ extraído pelo oxalato ácido de amônio (Ox); $\mathrm{Fe}_{\mathrm{S}}=\mathrm{Fe}_{2} \mathrm{O}_{3}$ extraído pelo ataque sulfúrico; $\mathrm{T}=\mathrm{CTC}$ a pH 7,0; $\mathrm{SE}=$ superfície específica; $\mathrm{MO}=$ matéria orgânica.

Quadro 3. Granulometria, atributos mineralógicos e relações destes para os Latossolos estudados ${ }^{(1)}$

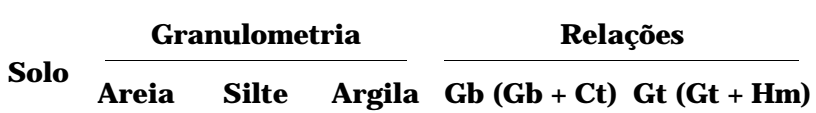

\begin{tabular}{|c|c|c|c|c|c|}
\hline \multirow[b]{2}{*}{1} & \multicolumn{3}{|c|}{$\mathrm{g} \mathrm{kg}^{-1}$} & \multirow[b]{2}{*}{0,12} & \multirow[b]{2}{*}{0,09} \\
\hline & 170 & 160 & 670 & & \\
\hline 2 & 470 & 60 & 470 & 0,27 & 0,07 \\
\hline 3 & 60 & 150 & 790 & 0,10 & 0,05 \\
\hline 4 & 290 & 80 & 630 & 0,33 & 0,42 \\
\hline 5 & 60 & 80 & 860 & 0,35 & 0,08 \\
\hline 6 & 860 & 1 & 139 & 0,10 & 0,20 \\
\hline 7 & 240 & 110 & 650 & 0,22 & 0,12 \\
\hline 8 & 300 & 100 & 600 & 0,37 & 0,36 \\
\hline 9 & 660 & 1 & 339 & 0,45 & 0,17 \\
\hline 10 & 180 & 100 & 720 & 0,74 & 0,46 \\
\hline 11 & 170 & 110 & 720 & 0,55 & 1,00 \\
\hline 12 & 120 & 30 & 850 & 0,34 & 0,16 \\
\hline 13 & 360 & 100 & 540 & 0,96 & 0,37 \\
\hline 14 & 370 & 110 & 520 & 0,17 & 0,37 \\
\hline 15 & 550 & 10 & 440 & 0,06 & 1,00 \\
\hline 16 & 800 & 50 & 150 & 0,50 & 1,00 \\
\hline 17 & 600 & 40 & 360 & 0,07 & 1,00 \\
\hline
\end{tabular}

(1) $\mathrm{Ct}=$ caulinita; $\mathrm{Gb}=$ gibbsita; $\mathrm{Gt}=$ goethita; $\mathrm{Hm}=$ hematita.
Para medir as quantidades de ácido ou base necessárias para ajustar o pH dos solos ao valor estabel ecido na determinação da CMAPb, 0,3 g da fração terra fina seca ao ar de cada solo, em suspensão com $\mathrm{Ca}\left(\mathrm{NO}_{3}\right)_{2}$ 0,005 mol L-1 (relação solo:sol ução 1:67), foram col ocados para reagir com 0,$0 ; 1,0 ; 2,0$ e $4,0 \mathrm{~mL}$ de solução saturada de $\mathrm{Ca}(\mathrm{OH})_{2}$ (concentração final de $\mathrm{Ca}(\mathrm{OH})_{2}$ igual a $0,01112 \mathrm{~mol} \mathrm{~L}^{-1}$ ) e com 0,$0 ; 1,0$ e $2,0 \mathrm{~mL}$ de $\mathrm{HNO}_{3}$ $0,007 \mathrm{~mol} \mathrm{~L}^{-1}$, durante $72 \mathrm{~h}$, alternando-se $12 \mathrm{~h}$ de agitação e $12 \mathrm{~h}$ de repouso. $\mathrm{O}$ pH das amostras foi medido de 12 em $12 \mathrm{~h}$, sendo considerado estável quando a variação entre as medições foi menor que 0,1 unidade, o que ocorreu entre 60 e $72 \mathrm{~h}$.

Estabeleceram-se equações de regressão, calculando-se, assim, as quantidades necessárias de ácido ou base para o ajuste do $\mathrm{pH}$. O sal usado foi o $\mathrm{Ca}\left(\mathrm{NO}_{3}\right)_{2}$, por ser o $\mathrm{Ca}^{2+}$ o principal cátion no complexo sortivo de Latossol os brasileiros e o $\mathrm{NO}_{3}{ }^{-}$ apresentar pequena capacidade deformar par iônico com metais em solução (Lindsay, 1979).

Para determinar a capacidade máxima de adsorção de chumbo (CMAPb), foram pesados $0,3 \mathrm{~g}$ de amostras de cada solo em tubos de centrífuga de $50 \mathrm{~mL}$ aos quais foram adicionados $20 \mathrm{~mL}$ de $\mathrm{Ca}\left(\mathrm{NO}_{3}\right)_{2}$ 0,005 mol L-1. Em seguida, colocaram-se as quantidades necessárias de solução saturada de $\mathrm{Ca}(\mathrm{OH})_{2}$ ou $\mathrm{HNO}_{3}$ 0,007 mol L-1 para ajustar o pH 
das suspensões a 5,5. Adicionaram-se, então, a cada tubo, $10 \mathrm{~mL}$ de $\mathrm{Pb}\left(\mathrm{NO}_{3}\right)_{2} 0,45 \mathrm{mmol} \mathrm{L}-1 \mathrm{em} \mathrm{Ca}\left(\mathrm{NO}_{3}\right)_{2}$ $0,005 \mathrm{~mol} \mathrm{~L}^{-1}\left(\mathrm{pH} 5,5\right.$, força iônica $0,015 \mathrm{~mol} \mathrm{~L}^{-1}$, relação solo:solução final 1:100).

As amostras assim permaneceram por $72 \mathrm{~h}$, alternando-se $12 \mathrm{~h}$ de repouso e $12 \mathrm{~h}$ sob agitação. A pós este período, as sol uções foram centrifugadas, o sobrenadante coletado para leitura de $\mathrm{Pb}$ e o resíduo pesado para determinação da massa de solução retida. Aoresíduoremanescenteadicionaramse $30 \mathrm{~mL}$ de $\mathrm{Pb}\left(\mathrm{NO}_{3}\right)_{2}$ 0,45 mmol L-1 em Ca $\left(\mathrm{NO}_{3}\right)_{2}$. Após um período de reação de $72 \mathrm{~h}$, as amostras for am centrifugadas e o sobrenadante col etado para leitura de $\mathrm{Pb}$. Este procedimento foi repetido atéque o incremento na adsorção fosse, em média, inferior a $2 \%$, o que foi conseguido com 11 séries de reações. Todas as operações foram realizadas com três repetições.

No total, foram adicionados aos solos aproximadamente $0,465 \mathrm{~mol} \mathrm{~kg}^{-1}$ dePb desolo. Esta mesma quantidade adicionada de uma só vez numa solução relação solo:solução 1:100 requereria uma solução 4,6 mmol L-1 de $\mathrm{Pb}$, o que poderia resultar em precipitação de $\mathrm{Pb}(\mathrm{OH})_{2}$ na solução a $\mathrm{pH} 5,5$ (Allison et al., 1990).

Este procedimento, usando reações repetidas e concentrações mais baixas, tem sido preferido em relação àquele que emprega uma reação única com soluções mais concentradas (por exemplo, determinação da capacidade máxima de adsorção, empregando-se isoterma de Langmuir), para evitar a formação de preci pitados em solução (Guilherme \& Anderson, 1998). A quantidade adsorvida foi calculada pela diferença entre o $\mathrm{Pb}$ adicionado e o remanescente na solução de equilíbrio após cada série dereação, sendoa adsorção máxima o resultado do somatório das quantidades adsorvidas a cada série. Após a 11 a bateria de reações, foram adicionados, a cada tubo, $30 \mathrm{~mL}$ de $\mathrm{Ca}\left(\mathrm{NO}_{3}\right)_{2}$ $0,005 \mathrm{~mol} \mathrm{~L}^{-1}(\mathrm{pH} \mathrm{5,5)}$ para determinação da dessorção do $\mathrm{Pb}$ retido. Após $72 \mathrm{~h}$ de reação, as amostras foram centrifugadas e o sobrenadante col etado para leitura. O Pb dessorvido foi cal culado, descontando-se aquel eproveniente da sol ução retida após a retirada do sobrenadante do experimento de adsorção. Correlações dePearson foram estabelecidas entre os resultados da CMAPb eos atributos físicos, quími cos e mineralógicos dos Latossol os estudados.

\section{RESULTADOSE DISCUSSÃO}

\section{Teor total}

Os teores totais de Pb (Quadro 4), após extração com água régia, encontram-se dentro dos teores médios relatados para solos não contaminados. Entretanto, deve-se considerar que a água régia remove de 70-90\% do elemento presenteno sol o (Ure, 1990). Relatos na literatura citam teores de $\mathrm{Pb}$ em solos de 10 a $67 \mathrm{mg} \mathrm{kg}^{-1}$ (Kabata-Pendias \& Pendias, 1992) com média de $16 \mathrm{mg} \mathrm{kg}^{-1}$ (Alloway, 1990). No Brasil, são relatados teores de 20,4 a $58,9 \mathrm{mg} \mathrm{kg}^{-1}$ (J ordão et al., 1996), 24 a $184 \mathrm{mg} \mathrm{kg}^{-1}$ de Pb (Ker et al., 1993) e $614 \mathrm{mg} \mathrm{kg}^{-1}$ de Pb (Ribeiro Filho et al., 1999).

Demaneira geral, os sol os das regi ões sul esudeste do Brasil (solos 1 a 12, excetuando-se o solo 7) apresentaram maiores teores de $\mathrm{Pb}$ que os sol os das regiões norte e nordeste, indicando maior enriquecimento com este elemento nos solos dessas regiões. Segundo Alloway (1990) e Kabata Pendias \& Pendias (1992), o teor de chumbo em solos não contaminados varia muito, dependendo do material de origem. Dentre os sol os que apresentaram teores de $\mathrm{Pb}$ acima da média, apenas o sol o 6 é originado de arenito, enquanto os demais são originados de rochas máficas. J á os sol os que apresentaram teores abaixo da média são originados de diferentes materiais, desdegnaisse-granítico atésedimentos de constituição diversa. Nota-se, então, maior contribuição da rocha máfica para el evação dos teores de $\mathrm{Pb}$ nos sol os estudados.

Outro fato que provavelmente contribui para aumentar os teores de chumbo nos solos da região sul e sudeste está relacionado com a deposição atmosférica, uma vez que, nestas regiões, há maior concentração de indústrias e maior tráfego de veículos que, previamenteà década de 80 , utilizavam gasolina com $\mathrm{Pb}$.

\section{Capacidade máxima de adsorção de chumbo}

Os Latossolos estudados apresentaram grande capacidade para reter o Pb (Quadro 4), conforme já verificado para sol os de regiões de clima temperado (Zimdahl \& Skogerboe, 1977; Harter, 1979). Os solos que apresentaram menor capacidade adsortiva foram o solo 16 (L atossolo Vermelho-Amarelo) e o 17 (L atossolo Amarelo), sendo as maiores capacidades obtidas para os solos 15 (Latossolo Vermel ho-Amarelo) e 3 (L atossolo Roxo) (Quadro 4). A diferença mais marcante entre os dois Latossol os Vermel ho-Amarel os (solos 15 e 16) é que o de menor CMAPb (solo 16) é originado de arenito e contém menor quantidade de caulinita (Quadro 3). Dentre os sol os que apresentaram CMAPb acima da média geral, estão todos os Latossolos Roxos e a maioria dos Latossolos Vermel ho-E scuros. Esse fato indica que a classe do solo em associação ao seu material de origem exerce marcante influência sobre o seu potencial adsorvedor, o que é demonstrado pelas correlações significativas obtidas da CMAP b eal guns atributos dos sol os (Quadro 5).

Foi feita análise de regressão múltipla entre a CMAPb eos atributos químicos, físicos emineralógicos dos solos estudados, não tendo sido detectado atributo que pudesse, isoladamente ou em conjunto, 
Quadro 4. Teores totais, capaci dade máxi ma de adsorção de Pb (CMAPb), quanti dade de Pb dessorvido e fração de $\mathrm{Pb}$ dessorvido ( b $_{\text {dessorvido }}$ (CMAPb) dos Latossolos estudados ${ }^{(1)}$

\begin{tabular}{|c|c|c|c|c|c|}
\hline Solo & Pb total & CMAPb & CMAPb & Pb dessorvido & Fração dessorvida \\
\hline & \multicolumn{2}{|c|}{$\mathrm{mg} \mathrm{kg}^{-1}$} & $\mathrm{mmol} \mathrm{kg}{ }^{-1}$ & $\mathrm{mg} \mathrm{kg}^{-1}$ & \\
\hline 1 & 21,9 & $15.409,0 \mathrm{bc}$ & 74,4 & $33,9 \mathrm{bc}$ & 0,0022 \\
\hline 2 & 19,3 & $12.842,0$ cde & 62,0 & $33,8 \mathrm{bc}$ & 0,0026 \\
\hline 3 & 22,0 & $17.154,0 \mathrm{ab}$ & 82,8 & 45,9 a & 0,0027 \\
\hline 4 & 22,9 & $15.107,0 \mathrm{bcd}$ & 72,9 & $36,7 \mathrm{~b}$ & 0,0017 \\
\hline 5 & 19,0 & $12.179,0$ de & 58,8 & $29,6 \mathrm{bcd}$ & 0,0024 \\
\hline 6 & 18,2 & $6.911,0 \mathrm{~g}$ & 33,4 & $1,9 \mathrm{~g}$ & 0,0009 \\
\hline 7 & 20,1 & $14.953,0 \mathrm{bcd}$ & 72,2 & $29,2 \mathrm{bcd}$ & 0,0020 \\
\hline 8 & 20,4 & $12.139,0$ de & 58,6 & 26,5 cdef & 0,0022 \\
\hline 9 & 15,9 & $7.056,0 \mathrm{~g}$ & 34,1 & $18,8 \mathrm{f}$ & 0,0027 \\
\hline 10 & 17,4 & $10.892,0$ ef & 52,6 & 21,8 def & 0,0020 \\
\hline 11 & 14,1 & $9.947,0$ efg & 48,0 & 26,2 cdef & 0,0026 \\
\hline 12 & 30,5 & $8.852,0 \mathrm{fg}$ & 42,7 & $32,1 \mathrm{bc}$ & 0,0036 \\
\hline 13 & 15,0 & $12.647,0$ cde & 61,0 & 20,7 ef & 0,0016 \\
\hline 14 & 15,1 & $12.030,0$ de & 58,1 & 28,9 bcde & 0,0024 \\
\hline 15 & 13,9 & $19.465,0 \mathrm{a}$ & 93,9 & 28,6 bcde & 0,0015 \\
\hline 16 & 14,1 & $2.327,0 \mathrm{~h}$ & 11,2 & $1,8 \mathrm{~g}$ & 0,0006 \\
\hline 17 & 6,1 & $2.115,0 \mathrm{~h}$ & 10,2 & $6,4 \mathrm{~g}$ & 0,0027 \\
\hline Média & 18,0 & $11.295,6$ & 54,5 & 24,9 & 0,0021 \\
\hline
\end{tabular}

Médias seguidas pelas mesmas letras não diferem entre si (Tukey 5\%).

(1) Valores de CMAPb em mmol kg-1 estão incluídos visando à comparação com os valores de CTC a pH 7,0 do quadro 2, lembrandose que $1 \mathrm{mmol} \mathrm{kg}^{-1}$ de $\mathrm{Pb}=2 \mathrm{mmol}_{\mathrm{c}} \mathrm{kg}^{-1}$ de $\mathrm{Pb}$.

Quadro 5. Coeficientes de correlação de Pearson (r) entre alguns atributos dos solos e a capacidade máxima de adsorção de Pb (CMAPb)

\begin{tabular}{|c|c|c|c|}
\hline Atributo & $\mathbf{r}$ & Atributo & $\mathbf{r}$ \\
\hline Mat. Orgânica & 0,33 & Silte & $0,46^{*}$ \\
\hline Sup. Específica & $0,75^{* *}$ & Argila & $0,43^{*}$ \\
\hline $\mathrm{Vm}-\mathrm{OH}^{1}$ & $0,43^{*}$ & $\mathrm{Kr}$ & 0,08 \\
\hline Caulinita (Ct) & $0,46 *$ & $\mathrm{Ki}$ & $0,44^{*}$ \\
\hline Gibbsita (Gb) & 0,11 & СТС а pH 7,0 & $0,51^{*}$ \\
\hline Goethita (Gt) & 0,15 & FedCB & $0,45^{*}$ \\
\hline Hematita $(\mathrm{Hm})$ & $0,46^{*}$ & Feox & $0,53^{*}$ \\
\hline Maghemita & $0,42 *$ & $\mathrm{Fe} \times \mathrm{x} / \mathrm{F}$ edcB & 0,01 \\
\hline $\mathrm{Al}_{2} \mathrm{O}_{3} / \mathrm{Fe}_{2} \mathrm{O}_{3}$ & $-0,57^{*}$ & F eDcB $/ F$ eataque sulfúrico & 0,18 \\
\hline $\mathrm{Gt} /(\mathrm{Gt}+\mathrm{Hm})$ & $-0,31$ & & \\
\hline $\mathrm{Gb} /(\mathrm{Gb}+\mathrm{Ct})$ & $-0,17$ & & \\
\hline $\mathrm{Fe}_{2} \mathrm{O}_{3}{ }^{2}$ & $0,48^{*}$ & & \\
\hline $\mathrm{SiO}_{2}^{2}$ & $0,55^{*}$ & & \\
\hline $\mathrm{Al}_{2} \mathrm{O}_{3}{ }^{2}$ & 0,29 & & \\
\hline
\end{tabular}

*,**: Significativos a 5 e $1 \%$, respectivamente.

(1) Vermiculita com hidróxi entre-camadas. (2) Provenientes do ataque sulfúrico.

predizer a capacidade adsortiva dos sol os para $\mathrm{Pb}$. Isto se deve, provavel mente, ao fato de os atributos dos solos interagirem entre si, não sendo possível distinguir isoladamentea contribuição dos atributos estudados. Entretanto, este fato não invalida as correlações simples, tais como as de Pearson, uma vez que elas apenas refletem a extensão de uma relação linear entre dois conjuntos de dados.

Embora a matéria orgânica presente nos solos contribua grandemente para reduzir o seu ponto de carga zero (PCZ) e, conseqüentemente, aumentar a densidade superficial de cargas negativas (Silva et al., 1996), não houve correlação entre seu teor e a CMAPb dos solos estudados. Segundo Zimdahl \& Skogerboe (1977), a maior parte do chumbo imobilizado pelos solos está associada à matéria orgânica, ao passo que Harter (1979) não encontrou correl ação entre a CMAPb de 15 sol os (horizontes A e B) dos EUA e a matéria orgânica. Uma vez que a natureza da matéria orgânica presente nos solos é muito variável, torna-se difícil qualquer consideração a respeito da falta de correlação observada neste trabalho. De acordo com Lopes \& Cox (1977), é possível que $\mathrm{Al}^{3+}$ (etalvez $\mathrm{Fe}^{3+}$ ) forme complexos com ligantes orgânicos bloqueando os sítios de troca de cátions e a compl exação de metais.

A presença de vermiculita com hidróxi entrecamadas contribui para o aumento das cargas negativas e CTC dos solos e correlaciona-se positivamente com a CMAPb. As correlações positivas verificadas entre a CMAPb e os teores de

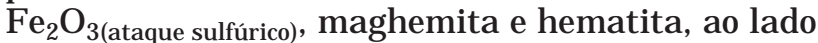
da sua falta de correlação com goethita, justificam as mai ores capacidades de adsorção obtidas para os Latossolos Roxos e Latossolos Vermelho-E scuros, 
quando comparados com os Latossolos VermelhoAmarelos e Amarelos. A correlação positiva com hematita está de acordo com a alta afinidade deste óxido por $\mathrm{Pb}$, conforme relatado por McKenzie (1980).

Ainda com relação aos óxidos, verifica-se que as menores capaci dades adsortivas foram encontradas nos sol os com menor teor de Fe-Ox. Shuman (1977) observou que a adsorção de Zn em óxidos de Fee Al mal cristalizados é cerca de 10 vezes maior do que em óxi dos cristalinos. Entretanto, Y ong \& MacDonald (1997), estudando a adsor ção de Pb por um solo com altos teores de ilita, observaram que a remoção de óxidos mal cristalizados resultou em aumento na capacidade de retenção de $\mathrm{Pb}$ dos solos. Maiores concentrações de $\mathrm{Pb}$ em frações oxídicas têm sido documentadas em vários trabalhos (Matos et al., 1996; Arona \& Romero, 1996).

A ausência de correlação entre a CMAPb e o teor de goethita, que, na forma sintética, é um dos óxidos de ferro mais usados em experimentos de adsorção de metais (McKenzie, 1980; Padmanabham, 1983; Coughlin \& Stone, 1995), está provavelmente relacionada com o fato de os solos aqui estudados apresentarem menores quantidades deste material em relação à hematita, excetuando-se os solos 11, 15, 16 e 17 (Quadro 3).

A correlação positiva obtida com a CTC a pH 7,0 era esperada, uma vez que oíon $\mathrm{Pb}$, sendo um cátion, é adsorvido nos sítios de cargas negativas dos colóides do solo. Observa-se, entretanto, que a maioria dos solos apresentou CMAPb maior que a CTC a pH 7,0 (Quadros 2 e4). Considerando que um mmol dePb correspondea dois $\mathrm{mmol}_{c}$, então somente os solos 2, 16 e 17 têm CTC a pH 7,0 maior que a CMAPb. Abd-Elfattah \& Wada (1981) verificaram esta adsorção extra (maior quea CTC) dePb e outros metais para sol os que continham al ofana, imogol ita ou óxidos de ferro.

Este fato evidencia que a adsorção de $\mathrm{Pb}$ não constitui unicamente um processo de atração eletrostática e indica que ele é adsorvido de forma específica, uma vez que a adsorção de íons via formação de complexos de esfera interna pode ocorrer independentemente da carga superficial (Sparks, 1995). Evidências adicionais de adsorção específica de $\mathrm{Pb}$ em Latossolos são relatadas por Pierangeli et al. (2001), em experimento com variação da força iônica da solução de equilíbrio.

Em sol os de cargas variáveis, é difícil distinguir a contribuição de cada um de seus componentes na adsorção de cátions metáli cos (Sposito, 1984). Mesmo em se tratando de minerais puros, a capacidade de adsorção de determinado óxido ou argilomineral depende do seu grau de cristalinidade, que é extremamente variável com a idade e condições ambientais de sua formação. I nfluem, ainda neste processo, o tamanho e a morfol ogia dos cristais.

\section{Dessorção}

Demaneira geral, os sol os que adsorveram menos dessorveram também menor quantidade de $\mathrm{Pb}$ (Quadro 4). A fração dessorvida decresceu de 0,0036 (solo 12-Latossolo Vermelho-E scuro) para 0,0006 (solo 16-Latossolo Vermel ho-Amarelo): ou seja, em média, cerca de $99,7 \%$ do $\mathrm{Pb}$ adsorvido permaneceu retido no solo após a dessorção com $\mathrm{Ca}\left(\mathrm{NO}_{3}\right)_{2}$ $0,015 \mathrm{~mol} \mathrm{~L}^{-1}$ por $72 \mathrm{~h}$.

Trabalhos realizados com materiais puros apresentaram resultados contraditórios com relação à dessorção de $\mathrm{Pb}$ (Padmanabham, 1983; Coughlin \& Stone, 1995), tendo sido creditados os maiores valores dessorvidos para $\mathrm{Pb}$, com relação a outros metais, ao seu grande raio iônico (124 pm) comparado àquele de outros cátions metálicos.

Fica difícil comparar os trabalhos, uma vez que os resultados aqui obtidos referem-se à dessorção de $\mathrm{Pb}$ após a adsor ção máxima desse el emento pelo solo. O fato de considerável quantidade de $\mathrm{Pb}$ ter permanecido adsorvida após os solos terem sido submetidos à dessorção por $72 \mathrm{~h}$ parece confirmar que parte do chumbo adsorvido é retida por forças específicas (quimi osor ção) em vez desi mples atração el etrostática, ou, então, como o tempo de contato das amostras com o chumbo durante o período de adsorção foi relativamente longo (mais de 30 dias), parte do contaminante pode ter-se vagarosamente difundido para o interior da matriz dos sol os através de microporos, permanecendo em formas não-lábeis (Barrow, 1989; Axe \& Anderson, 1998). Evidências de que o mai or tempo de contato durante a adsorção pode causar uma redução na dessorção percentual de metais são apresentadas por Guilherme (1997) e Guilherme \& Anderson (1997), em experimento com cobre em amostras de Latossolos.

\section{CONCLUSÕES}

1. Os teores totais de $\mathrm{Pb}$ nos solos estudados mostraram-se relacionados com seu material de origem, sendo mais elevados nas regiões sul e sudeste, reflexo da maior contribuição de rochas máficas.

2. Os Latossolos estudados neste trabalho apresentaram alta capacidade de retenção de $\mathrm{Pb}$ ( 2.115 a $19.465 \mathrm{mg} \mathrm{kg}^{-1}$, com média de $11.296 \mathrm{mg} \mathrm{kg}^{-1}$ ), contrariando o que seria esperado para solos intemperizados, com mineralogia dominada por caulinita e, em menores proporções, por óxidos de FeeAl.

3. Dos $17 \mathrm{~L}$ atossol os estudados, 14 apresentaram CMAPb superior à CTC a pH 7,0, indicando que a adsorção de $\mathrm{Pb}$ não ocorreu apenas por meio de atração el etrostática. 


\section{LITERATURA CITADA}

ABD-ELFATTAH, A. \& WADA, K. Adsorption of lead, copper, zinc, cobalt, and cadmium by soils that differ in cationexchange materials. J . Soil Sci., 32:271-283, 1981.

ABREU, C.A.; ABREU, M.F. \& ANDRADE, J .C. Distribuição de chumbo no perfil de solo avaliada pelas soluções de DTPA e Mehlich-3. Bragantia, 57:185-192, 1998.

ALLISON, J.D.; BROWN, D.S. \& NOVO-GRADAC, K.J . MINTEQA2/PRODEFA2, a geochemical assessment model for environmental systems. Version 3.00 user's manual. EPA-600/3-91-021. Athens, USEPA, 1990.

ALLOWAY, B.J. Heavy metals in soils. New York, J ohn Wiley, 1990. 339p.

AMARAL SOBRINHO, N.M.B.; COSTA, L.M.; OLIVEIRA, C. \& VELOSO, A.C.X. Metais pesados em alguns solos e corretivos. R. Bras. Ci. Solo, 16:271-276, 1992.

ARONA, A.B. \& ROMERO, F. Fractionation of lead in soils and its influence on the extractive cleaning with EDTA. Environ. Technol., 17:63-70, 1996.

AXE, L. \& ANDERSON, P.R. Intraparticle diffusion of metal contaminants in amorphous oxide minerals. In: J ENNE, E.A., ed. Adsorption of metals by geomedia: variables, mechanisms, and model applications. San Diego, Academic Press, 1998. p.193- 200.

BARROW, N.J . The reaction of plant nutrients and pollutants with soils: II. Effect of pH. Soil Sci., 153:195-204, 1989.

BASTA, N.T. \& TABATABAI, M.A. Effect of cropping systems on adsorption of metals by soils: II. Effect of pH. Soil Sci., 153:195-204, 1992.

CHANEY, R.L. Sludge utilization, land application and food chain impact. In: The biocycle to the art and science of composting. Pennsylvania, G.J . Press, 1991. p.240-253.

COUGHLIN, B.R. \& STONE, A.T. Nonreversible adsorption of divalent metal ions $\left(\mathrm{Mn}^{\prime \prime}, \mathrm{Co}^{\prime \prime}, \mathrm{Ni}^{\prime \prime}, \mathrm{Cu}^{\prime \prime}\right.$ and $\left.\mathrm{Pb}^{\prime \prime}\right)$ onto goethite: Effects of acidification, $\mathrm{Fe}^{\mathrm{ll}}$ addition, and picolinic acid addition. Environ. Sci. Technol., 29:2445-2455, 1995.

CRAVO, M.S.; MURAOKA, T. \& GINÉ, M.F. Caracterização química de compostos de lixo urbano de algumas usinas brasileiras. R. Bras. Ci. Solo, 22:547-553, 1998.

DAY, P.R. Particle fractionation and particle-size analysis. In: BLACK, C.A., ed. Methods of soil analysis. Madison, American Society of Agronomy, 1965. v.1. p.545-566.

EMPRESA BRASILEIRA DE PESQUISA AGROPECUÁRIA EMBRAPA. Manual de métodos de análise do solo. Rio de J aneiro, Centro Nacional dePesquisa de Solos, 1997. 212p.

GUILHERME, L.R.G. Copper adsorption/desorption in phosphate- and sludge-treated Oxisols: kinetics and effects of aging and $\mathrm{pH}$. East Lansing, Michigan State University, 1997. 92p. (Tese de Doutorado)

GUILHERME, L.R.G. \& ANDERSON, S.J . Cinética de dessorção de Cu em Latossolos: efeito do tempo de contato durante a adsorção. In: CONGRESSO BRASILEIRO DE CIÊNCIA DO SOLO, 25., Rio deJ aneiro, 1997. Anais. Rio deJ aneiro, Sociedade Brasileira de Ciência do Solo, 1997. (CD ROM)
GUILHERME, L.R.G. \& ANDERSON, S.J . Copper sorption kinetics and sorption hysteresis in two oxide-rich soils (Oxisols): Effect of phosphate pretreatment. In: JENNE, E.A., ed. Adsorption of metals by geomedia: variables, mechanisms, and model applications. San Diego, Academic Press, 1998. p.209-228.

HARTER, R.D. Adsorption of copper and lead by Ap and B2 horizons of several Northeastern United States Soils. Soil Sci. Soc. Am. J ., 43:679-683, 1979.

HEILMAN, M.D.; CARTER, D.L. \& GONZALEZ, C.L. The ethylene glycol monoethyl ether (EGME) technique for determining soil surface area. Soil Sci., 100:409-413, 1965.

J ENNE, E.A. Adsorption of metals by geomedia: Data analysis, models, controlling factors, and related issues. In:J ENNE, E.A., ed. Adsorption of metals by geomedia: variables, mechanisms, and model applications. San Diego, Academic Press, 1998. p.1-73.

J ORDÃO, C.P.; PEREIRA, J .C.; BRUNE, W.; PEREIRA, J .L. \& BRAATHEN, P.C. Heavy metal dispersion from industrial wastes in the Vale do Aço, Minas Gerais, Brazil. Environ. Technol., 17:489-500, 1996.

KABATA-PENDIAS, A. \& PENDIAS, H. Trace elements in soils and plants. 2.ed. Boca Raton, CRC Press, 1992. 365p.

KÄMPF, N. \& SCHWERTMANN, U. The $5 \mathrm{M}-\mathrm{NaOH}$ concentration treatment for iron oxides in soils. Clays Clay Miner., 30:401408, 1982

KER, J .C.; MOTTA, P.E.F.; RESENDE, M.; CARVALHO FILHO, A. \& ARAÚJ O, W.S. Elementos traços em L atossolos Roxos desenvolvidos de diferentes materiais de origem. In: CONGRESSO BRASILEIRO DE CIÊNCIA DO SOLO, 24., Goiânia, 1993. Resumo. Goiânia, Sociedade Brasileira de Ciência do Solo, 1993. p.319-320.

LANGENBACH, T.; PFEIFER, W.; FREIRE, L.R.; SARPA, M. \& PAIM, S. Heavy metals in sludgefrom the sewagetreatment plant of Rio de J aneiro. Environ. Technol., 15:997-1000, 1994.

LINDSAY, W.L. Lead. In: LINDSAY, W. L. Chemical equilibria in soils. New York, Wiley-Interscience, 1979. p.328-342

LOPES, A.S. \& COX, F.R. A survey of the fertility status of surface soils under "Cerrado" vegetation in Brazil. Soil Sci. Soc. Am. J ., 41:742-747, 1977.

MATOS, A.T. Fatores deretardamento ecoeficientes de dispersãodifusão do zinco,cádmio, cobre e chumbo em solos do município deViçosa. Viçosa, UniversidadeF ederal deViçosa, 1995. 110p. (Tese de Doutorado)

MATOS, A.T.; FONTES, M.P.F.; J ORDÃO, C.P. \& COSTA, L.M. Mobilidade e formas de retenção de metais pesados em Latossolo Vermelho-Amarelo. R. Bras. Ci. Solo, 20:379-386, 1996.

McBRIDE, M.B. Reactions controlling heavy metal solubility in soils. Adv. Soil Sci., 10:1-56, 1989.

MCBRIDE, M.B. Environmental chemistry of soils. New York, Oxford University Press, 1994. 406p.

MCKENZIE, R.M. The adsorption of lead and other heavy metals on oxides of manganese and iron. Aust. J . Soil Res., 18:61$73,1980$. 
MEHRA, O.P. \& J ACKSON, M.L. I ron oxide removal from soils and clays by dithionite-citratesystem buffered with sodium bicarbonate. Clays Clay Miner., 7:317-327, 1960.

PADMANABHAM, M. Comparative study of the adsorptiondesorption behaviour of copper(II), zinc(II), cobalt(II) and lead(II) at the goethite-sol ution interface, Aust. J . Soil Res., 21:515-525, 1983.

PIERANGELI, M.A.P.; GUILHERME, L.R.G.; OLIVEIRA, L.R.; CURI, N. \& SILVA, M.L.N. Efeito da força iônica da solução de equilíbrio sobre a adsorção-dessorção de chumbo em Latossolos brasileiros. Pesq. Agropec. Bras., 2001. (aceito para publicação)

RIBEIRO-FILHO, M.R.; CURI, N.; SIQUEIRA, J .O. \& MOTTA, P.E.F. Metais pesados em solos de áreas de rejeitos de indústria de processamento de zinco. R. Bras. Ci. Solo, 23:453-464, 1999.

SCHWERTMANN, U. Differenzierung der eisenoxide des bodens durch extraktion mit ammoniumoxalat-lösung. Z. Pflanzenernähr. Bodenkd., 105:194-202, 1964.

SHUMAN, L.M. Adsorption of Zn by Feand Al hydrous oxides as influenced by aging and pH. Soil Sci. Soc. Am. J ., 46:703706, 1977.

SILVA, M.L.N.; CURI, N.; MARQUES, J .J .G.S.M.; GUILHERME, L.R.G. \& LIMA, J.M. Ponto de efeito salino nulo e suas relações com propriedades mineralógicas e químicas de Latossolos brasileiros. Pesq. Agropec. Bras., 31:663-671, 1996.
SOUZA, J.A.; CURI, N. \& GUEDES, G.A.A. Relação entre mineralogia e adsorção-dessorção de fósforo em alguns Latossolos sob cerrado do Planalto Central. Ci. Prat., 15:103-111, 1991.

SPARKS, D.L. Environmental soil chemistry. San Diego, Academic Press, 1995. 237p.

SPOSITO, G. The surface chemistry of soils. New York, Oxford University Press, 1984. 234p.

STEVENSON, F.J. Stability constants of $\mathrm{Cu}^{2+}, \mathrm{Pb}^{2+}$, and $\mathrm{Cd}^{2+}$ complexes with humic acids. Soil Sci. Soc. Am. J ., 40:665672, 1976

URE, A.M. Methods of analysis of heavy metals in soils.. In: ALLOWAY, B.J . Heavy metals in soils. New York, J ohn Wiley, 1990. p.40-80.

VETTORI, L. Métodos de análise de solos. Rio de J aneiro, Ministério da Agricultura-Equipe de Pedologia eF ertilidade do Solo, 1969. 24p. (Boletim Técnico, 7)

YONG, R.N. \& MACDONALD, E. Influence of $\mathrm{pH}$, metal concentration, and soil components removal on retention of $\mathrm{Pb}$ and $\mathrm{Cu}$ by an illitic soil. In: JENNE, E.A., ed. Adsorption of metals by geomedia: variables, mechanisms, and model applications. San Diego, Academic Press, 1998. p.229-253.

ZIMDAHL, R.L. \& SKOGERBOE, R.D. Behavior of lead in soil. Environ. Sci. Technol., 11:1200-1207, 1977. 